This is an author produced version of a paper published in International Journal of Nursing Studies. This paper has been peer-reviewed but does not include the final publisher proof-corrections or journal pagination.

Citation for the published paper:

Soderstrom, Ing-Mari and Saveman, Britt-Inger and Benzein, Eva

"Interactions between family members and staff in intensive care units-An observation and interview study."

Int J Nurs Stud. 2005 Nov 23; [Epub ahead of print]

http://dx.doi.org/10.1016/j.ijnurstu.2005.10.005

Access to the published version may require journal subscription.

Published with permission from: Elsevier 
Interactions between family members and staff in intensive care units - an observation and interview study

\author{
Ing-Mari Söderström ${ }^{\mathrm{a}, \mathrm{b}^{*}}$ RNT , PhD student, Britt-Inger Saveman ${ }^{\mathrm{a}} \mathrm{RNT}$, \\ PhD, Eva Benzein ${ }^{\mathrm{a}} \mathrm{RNT}, \mathrm{PhD}$ \\ ${ }^{a}$ Department of Health and Behavioural Sciences, Kalmar University, S-391 82 Kalmar, Sweden and \\ ${ }^{\mathrm{b}}$ Department of Nursing, Faculty of Medicine, Lund University P.O. Box 157, SE-221 00 Lund, \\ Sweden
}

* Corresponding author. Tel: +46-480-446966; fax: +46-480-446955. E-mail address: ing-marie.soderstrom@hik.se 


\title{
Interactions between family members and staff in intensive care units - an observation and interview study
}

\begin{abstract}
The aim was to describe and interpret interactions between family members and staff in intensive care units. Interviews and observations were performed and analysed together by means of content analysis, resulting in two themes: Mutual understanding and Mutual misunderstanding. Family members who understood the explicit information and the implicit messages were open, adjusted well, were acknowledged and sometimes consoled by the staff. Those having difficulties understanding information and implicit messages drew back, did not adjust and were sometimes insulted by the staff. The results of this study may be a starting point for ICU staff to reflect on how family members are treated.
\end{abstract}

Key words: Intensive care, family members, staff, interactions, observations. 


\section{Introduction}

This study focuses on interactions between staff and family members with a critically ill family member cared for in intensive care units (ICU). The way interactions between family members and staff in ICUs are mutually experienced influences further interactions. Nurses' experiences of these interactions have been presented in an earlier study (Söderström et al., 2003), and the present study highlights the interactions focusing on family members. These interactions are of the utmost importance for supporting family members as the ICU context entails care situations where critically ill patients hover between life and death. ICUs are characterized by advanced technology, a high staff rate and a great intensity in interventions around the clock. Family members as well as patients can be overwhelmed with the stress of the alien environment and therefore have a wish to be close (Bijttebier et al., 2001), to encourage, help, protect (Burr, 1998) and follow what is happening with their critically ill family member (Jamerson, 1996). Furthermore, family members struggle with fears concerning the survival of the patient and strong feelings of despair and anxiety can arise (Burr, 1998, Hupcey, 1999). Often family members hide their feelings in front of the patient and other family members, leading to difficulties in communication (Hupcey, 1999, Titler et al., 1991) and to misunderstandings in interactions with the staff (Plowfield, 1999, Hupcey, 1999).

Nurses and physicians are to a great extent referred to family members for communication due to the critical state of the patients, but staff also have the responsibility to care for and create a confident and trustful context for family members. The unique ICU context requires that staff are aware of feelings and thoughts behind the 
façade of family members, in order to provide holistic care. Studies focusing on the interactions from the nurses' perspective disclose various potential problems in the interactions with family members, for example, nurses having a medical and technical perspective and limited time to care for family members (Söderström et al., 2003) and nurses who restrict visiting policies for families (Fox and Jeffrey, 1997).

Studies have focused on family members' needs at ICU, e.g. wanting the best possible care for the patient, maintaining hope and trying to obtain detailed information from staff (Molter, 1979). Both old and recent studies show how these needs were perceived as secondary to the patients' needs and that family members could not claim time from staff (Burr, 1998, Leske, 1986, Norris and Grove, 1986). Other studies have focused on experiences of family members (Lam and Beaulieu, 2004, Titler et al., 1991), changed life patterns (Van Horn, 2000), and ways of coping (Twibell, 1998) in a situation when one family member is critically ill. Conflicting information from staff during the stay in ICU, causing confusion, sadness and anger is also described (Hupcey, 1999). Kleiber (1994) found that nurses and physicians were supportive in their caring attitude and provided information and answered questions in a comprehensible and honest way, but did not offer any emotional support.

There are few studies explicitly focusing on interactions between family members and ICU staff and how these influence the family members. However, Hupcey (1998) interviewed family members $(n=10)$ and ICU nurses $(n=10)$ and found that family members wanted to develop a relationship with nurses, which would benefit the care of 
the patient, the possibility for families to receive information and be involved in decisions related to the patient. In a later study (Hupcey, 1999), the interactions between nurses and relatives in ICU were examined by interviewing nurses $(n=10)$, relatives $(n=11)$ and patients $(n=30)$. The relatives described how the nurses comforted them and cared for them as well as for the patient. However, the relatives were upset about some stressful situations, e.g. when they were not sufficiently informed and when nurses suddenly changed the policies.

Families in a neurological ICU $(\mathrm{n}=12)$ experienced helplessness and frustration about being in an unfamiliar environment, depending on strangers for caring and trying to obtain information. Visiting times were often restricted, but when family members gained access to the patient they experienced a sense of control. Family members felt that nurses did not trust them to be able to promote the patients' health (Plowfield, 1999). This is the only study we found based on observations of interactions.

Obviously, there is a lack of knowledge about family members' interactions with staff in ICUs. An observation and interview study might render a more comprehensive picture of these interactions.

\section{Aim}

The aim was to describe and interpret interactions between family members and staff in intensive care units with the focus on family members. 


\section{Methods}

A descriptive and interpretive design, including observations and interviews, was used to analyse interactions between family members and ICU staff. The choice of using observations was in accordance with Bogdevic (1999), who stated that if the aim is to study how activities and interactions give meaning to special behaviours or beliefs, this is an adequate method. Observations give the opportunity to grasp interactions which are lived but not conscious or articulated. The value of making observations is to "get backstage” and learn about the realities of a group’s experiences (Polit and Beck, 2004, p. 379). In addition, interviews were performed in order to grasp family members' experiences of the interactions with the staff. Data from observations and interviews were transcribed and analysed as a joint text. In this study, interactions mean all communication in a verbal or non-verbal way between family members and ICU staff. Staff include registered nurses, enrolled nurses and physicians.

\subsection{Patients, family members and settings}

Ten critically ill patients and their family members $(n=24)$ from three ICUs at a university hospital in the south of Sweden participated in this study. The inclusion criteria of the patients were: Critically ill over 15 years of age, cared for in a respirator with an expected care period in the ICU of at least one week and with one family member present. The inclusion criteria for the family members were: Being seven years or older (Doherty and Sandelowski, 1999) and Swedish-speaking.

The age of the patients varied between 15 and 84 years $(\mathrm{m}=58)$, three patients were 
women and seven were men. Four patients had multiple traumas after car accidents, three patients were diagnosed with stroke, one each with aortic aneurysm, heart infarction and unknown unconsciousness. All patients survived the ICU stay. The age of the family members varied from 14 to 73 years $(m=41)$. Six family members were spouses, eight each were sons or daughters, one a sister and one a grandmother.

The surgical, neurological and thoracic ICUs were organized in a similar way. The patients could be cared for in single rooms, two-bed rooms or rooms for four patients. One or two registered nurses (RN) and one enrolled nurse (EN) were accountable for each patient. Each RN could be accountable for 1-3 patients and the EN for 1-2 patients in the same room. Visiting was allowed around the clock after agreement with the RNs. About two thirds of the nurses were women.

\subsection{Procedure}

Before the study, the first author had training in the role of an observer of one family in an ICU at a local hospital. An observation schedule was tested but rejected for the main study as it was judged as too limited to describe the complex interactions.

Verbal and written information about the study was given to the ICU staff at each unit. The head nurse asked family members consecutively for permission for the first author to give further verbal and written information. The patients were all unconscious and unable to give consent; instead family members gave informed consent for themselves and for the patient. Three families declined participation due to being emotionally overwhelmed. 
One family did not agree to audio taping in the patient room, therefore only notes were taken. Data collection lasted about six months during 2003. The care period varied between three and fourteen days; those staying longer were observed more than the others. The study was approved by the Research Ethics Committee of the Medical Faculty of Lund University (LU 770-02).

\subsection{Observations}

The first author made non-participating observations in the patient room, sitting beside the wall having no verbal communication with the staff or the family members. If there was more than one patient in the room, the area around the patient was shielded. One member of the staff was always present in the room. Each family was observed on average five times, about 30 to 90 minutes at a time, mostly daytime. Field notes were made of the context and all interactions between family members and staff, answering questions such as who, when, what, how and where (Polit and Beck, 2004). There were totally about 65 hours of observations. All verbal communication was taped. The field notes also contained time marks enabling comparisons with the audio tapes. Afterwards, the observer documented her own experiences of the observations. The audio tapes were transcribed verbatim.

\subsection{Interviews}

At the end of the patient's intensive care period, the family members were interviewed individually about their experiences of the interactions. Twenty-four tape recorded interviews were performed in a quiet room in the ICUs. The family members were 
invited to tell about their experiences of the interactions with the staff. For example the following questions were used: "What did the staff say or do that was most helpful for you?" "Do you think that the staff understood how you experienced the situation?" "What did they do/say that made you think so?” Questions about experiences of observed situations were also asked. The interviews lasted between 40 to 90 minutes and were transcribed verbatim.

\subsection{Analysis}

A latent content analysis inspired by Catanzaro (1988) and Baxter (1994) was performed. The observations, the interviews and the primary analysis were performed by the first author, who has a preunderstanding as an anaesthetist nurse with clinical experience of working in ICUs and with an interest in family nursing. The process of analysis was hermeneutical, moving between the text and proposed plausible interpretations and between parts and the whole. Here we present a simplified picture of this circular process. The text from the interviews (approximately 150 pages), the observations (approximately 65 pages) together with the observer's reflections after the observations, was read through a couple of times to get immersed in the data. Notes about the content and ideas for further analysis were written in the margin. Meaning units were identified and condensed into codes. These codes were reflected on and categorized and similarities and differences between categories were sought and interpreted. Finally, threads of meaning (Baxter, 1994) through the categories were found and transformed into themes. The third author participated in this process. During the analysis, all three co-authors read parts of the texts and the codes and categories were discussed and finally the categories and the 
themes were adjusted and agreed on. Examples from the analysis are presented in Table 1.

\section{Result}

The initial interactions between staff and family members had a substantial effect on family members and influenced their further interactions with the staff. The interactions consisted of the RN's explicit information to family members about rules and policies of the ICU, the condition of the patient, and how to behave in front of the patient, which was highly valued by all family members. However, when saying this, staff also transferred implicit messages. For example, the RNs said, “you have full access to the unit”, but the implicit message was: “as long as you come at convenient times for us”. RNs said, “you can visit the patient whenever you want”, but meant "as long as you do not disturb us in our work” and "you can ask questions freely”, but the implicit message was "as long as we find them relevant”. Most family members understood the information and implicit messages from the beginning, i.e. they could crack the code of the ICU. These family members adjusted, were satisfied and well treated by the staff. There seemed to be a mutual understanding between family members and staff, ( $1^{\text {st }}$ theme). Other family members did not fully understand either the explicit information and/or the implicit messages, i.e. they had difficulties cracking the code of the ICU. They became increasingly confused, drew back or acted out by forced talking or asking a lot of questions. Gradually during the stay in ICU, the implicit messages became more clear through the verbal and non-verbal contact with the staff. Still there seemed to be a mutual 
misunderstanding between family members and staff, ( $2^{\text {nd }}$ theme). These family members were ignored and mistreated by the staff.

\subsection{Mutual understanding}

The open atmosphere and the possibility to stay in the unit and with the patient exceeded the family members' expectations. They understood the explicit information given by the staff and could also interpret the implicit messages, e.g. how the staff expected them to behave in order to stay in line. These family members experienced a balance between their demands, i.e. to visit the patient and get information continuously, and the response from the staff. Whether they questioned the system or not, they adjusted and were satisfied and some even felt consoled as persons, as they were acknowledged and confirmed by the staff.

\subsubsection{Interactions of adjustment and acknowledgement}

Through the continuous information, which family members understood and adjusted to, they experienced calmness and a sense of control. They fully relied on the medicaltechnical treatment. All family members who understood the explicit information and implicit messages adjusted to the system, told of interactions where they were acknowledged as family members and were satisfied with the staff and how the system worked.

One implicit message interpreted by the family members was that the staff were there for 
the patients and not for the family members. They adjusted to this, as it was in line with family members' expectations and preunderstanding before admission. The family members acted in a very careful and humble way, and if they needed help for themselves they said they had to seek this help elsewhere. Another implicit message, to which the family members also adjusted, was that they should not disturb or challenge the rules at the ICU. They stayed close to the patient, watching the monitoring and performing easy caring tasks for the patient, in accordance with instructions from the staff. They posed questions, mainly about equipment, alarms and the patient's condition. Since most information was delivered in the patient room, the family members said they had to stay there in order to get as much information as possible.

“Then you have to ask, you don't get told by everyone if you yourself don't ask... I've noticed that, if there's something you want to ask ... if there's something they're going to change or the tests show something, you might not find out about it straight away if you're not sitting in there." 1:3

The first information was often experienced as shocking, causing feelings of paralysis. However, receiving information continuously and being able to stay with the patient as long as they wanted, within reasonable limits, helped them cope with the situation. The meaning of "reasonable limits" was understood by these family members, and they adjusted to it. However, sometimes the staff had to point out the limits more explicitly and then family members adjusted immediately. 
'You can't sit here the whole time,' [staff said] when we wanted to at the start. 'You can sit outside and come in now and then instead, and we'll let you know if anything happens.' At first I felt that was, it was a bit unpleasant, but at the same time I felt that this is their work environment .... of course we can't sit there as much as we want." 9:1

Even if some information was contradictory, family members accepted this and adjusted to it. For example, family members were told that the patient could hear, but still most of the information was given at the bedside, talking over the head of the patient. Mostly the nurses gave straightforward and objective information without valuations or instilling false hope. However, the family members felt acknowledged when receiving information directly from the physicians. The family members also felt acknowledged, e.g. when the staff pointed out the importance of looking after one's own health, something which family members had not expected. The staff showed an interest in and posed questions about the family members’ physical health, e.g. if they had slept well and eaten sufficiently. The family members seemed to pay attention to advice about living as normally as possible and they went out now and then for a rest, a walk or to have something to eat. Concern on the part of the staff was experienced as helpful and supportive.

"Well, you know, when they pass there are always a few words. They can pat you on the shoulder, stop and talk to you, and the first day she said 'you should really 
lie down now,' so she came out with me and fixed a TV and water and said 'Lie down here and rest." "' 2:1

When the patients' condition was stable and the family members were in a good mood and seemed to get along well with the staff, there could be a lot of talking, chatting and laughing. The staff sometimes seemed to stay in the room only with the intention to talk to the family members about other things than the patient's care. This positive atmosphere, characterized by mutual respect created by family members and staff together, relieved the family members of their worries and was a way of enduring the situation. Being in this positive atmosphere, family members felt that they were accepted and not in the way, which was essential for their apprehension and satisfaction of the care as a whole.

"They [staff] talk about everything, about the disease of course, but you talk about other things too, general discussion of things which means that you feel accepted and then you feel that there is empathy in this emotional exchange because you can discuss everyday things, that's important." 2:2

The way the ICU staff treated the patient was of the utmost importance. Staff that were considered skilled, engaged, and capable of standing up for and protecting the patient were highly valued. If the patient was cared for with respect, the family members felt acknowledged and satisfied. 
"It's important for me as a family member to know that the staff actually care about their patient, that it's not just a job for them, even if it's a lot to ask. That's what makes the difference, whether you like them or not.” 10:2

Some family members understood the system, adjusted and were acknowledged, but were critical and questioned the care. When they perceived that the patient or other family members were unfairly treated, they complained in a straightforward way to one staff member, with whom they had good relationship. These family members were satisfied that they had the courage to lodge the family's complaints. They became spokesmen for other family members and protected the family if needed. After the complaints, these family members felt acknowledged and even more respected by the staff.

“It felt really good to speak my mind. If nobody says anything there isn't a chance that they'll act differently the next time, so you have to do it, I think." 9:1

\subsubsection{Interactions of consolation and confirmation}

Sometimes the family members were met and confirmed by the staff not only as family members but also as persons. A special contact seemed to grow between the staff and these family members, which led to an experience of a deeper emotional engagement from the staff, incorporating the whole family. When staff explained the condition of the patient in terms close to everyday language instead of explaining in medical terms, it helped the family members to understand. It also rendered a special feeling of trust. When the family members apprehended engagement and confirmation from the staff, it 
was easier to show the anxiety openly, and when they did they were consoled by the staff. For example, family members who were invited to talk about their experiences and their suffering were also confirmed by the staff by touches and hugs. One nurse invited a spouse to write her experiences down in a diary in order to alleviate suffering. However, only a few family members were confirmed by the staff in this way.

"Really nice. I feel security, great security [moved]. They are fantastic here. I don't think I've ever seen such good staff. They're just like you want them to be. You get close to them somehow, and they touch you so that you can let your feelings come out. It's a good way to come to terms with the situation.” 8:1

"They could see that I needed to cry. It was so obvious that they wanted to hug me. It was good that they dared to touch me, it felt nice." 7:1

\subsection{Mutual misunderstanding}

These family members had difficulties understanding the explicit information, e.g. special medical and technical terms about the illness and the equipment, and the implicit messages, e.g. how to behave in the ICU. Family members became insecure, which was shown in various ways in their behaviour. They were neglected and got less continuous daily information from the staff. The staff seemed to misunderstand the underlying feelings of the family members, making family members even more confused, having difficulties adjusting to the system. There was an imbalance between their own demands to be continuously informed and the response from the staff. 


\subsubsection{Interactions of emotional maladjustment and non-acknowledgement}

The family members in this group had difficulties understanding the explicit information and/or the implicit messages. Since they did not ask questions or show explicit interest towards the staff, they were not further acknowledged and thus they also received less continuous information. These family members questioned the system and the policy for how information was given. All the words in the information were analysed and taken into account, but family members still experienced confusion and unfair treatment. They said that their heads were empty, they did not know what to ask, or did not dare. Instead, they wanted help and support from other family members.

“... talking to the doctor...I leave that to the children. When they use hospital language that I don't understand, I don't get it at all. Do they do that a lot? Well, there was a doctor one evening, I had to go and get my niece because I couldn't understand what he meant." 1:4

Being a contact person for the family and receiving information was perceived as a difficult task. The other family members asked a lot of supplementary questions, which were difficult to answer. Not all family members adjusted to the policy of choosing one family member as a contact person.

Out of worries for the patient, the family members demanded to obtain instant information, e.g. about medical examinations. Their request was not in accordance with how the system functioned, e.g. the physicians could not always be at their immediate 
disposal. Family members who only visited the patients in the evenings seldom met the physicians and felt they were not sufficiently informed and not involved in the decision making. They did not understand the implicit message, that in order to be fully informed they had to be present during the daytime. Most family members did not complain to the staff when they were unsatisfied with the care or treatment. Thus the staff did not seem to understand their annoyance. They discussed the situations within the families and decided mostly to wait and see.

"It's all this waiting, to get a chance to talk to the doctor and the time passes and you don't know when they change shift, has the information been passed on? So that they know you still want to talk to the doctor, it's things like that you wonder about." 6:2

When the patient's condition became more critical, some family members were sitting at bedside, not asking questions and looking as if they were not paying any attention to the surroundings. Afterwards they told about experiences of being paralysed by fear. These strong emotions were concealed under a façade of unconcern, which staff failed to interpret. Consequently, family members were neither acknowledged nor confirmed in their suffering.

"Then you feel when you look at this screen with blood pressure and things like that, when it drops you get really ... panic ... almost, what's happening? Now I 
know nothing about health care, not like the children, they know about this ..." $1: 4$

Situations also occurred when the alarms went on frequently and the family members looked nervously in the direction of the staff, as if searching for help. In other situations, the family members sat crying at bedside. These family members were not paid attention to, the staff did not respond to the family members' open signs of anxiety. Often the staff seemed deeply engaged with other tasks, and did not take steps to interact, instead they prioritized the care of another patient in the room. Dissatisfaction with and complaints about the staff arose. The complaints mainly focused on the lack of information and the feeling of being abandoned by the staff.

(Starts to cry...) "Did you get any support from the staff? Not exactly from the staff, I don't think so. Did they see that you were sad? Yes. I think so. Did anyone react? No, not then, I didn't think so. Afterwards? No, not that I've noticed. How do you feel about that? Well, they have a lot to do too, they can't look after the family as well, and they have to give priory to the patient, that's the most important thing.” 1:3

The staff seldom asked family members questions of a more personal and emotional character. The family members were not offered the possibility to sit down and talk in a separate room, even if they showed signs of anguish, e.g. walking quickly in or out, or talking in a forced way. The family members accepted not getting emotional support for 
themselves but expressed worries for the others in the family. They wished, e.g. for someone who could listen and reassure them that it was a normal reaction they experienced, but they did not ask for it. When the patient was in a serious condition for a long time, the family members were offered the opportunity to talk to a social worker; even if they rather wanted to talk to the staff involved at the ICU instead, they were not offered this opportunity.

“I don't know, I don't really expect anything of the staff, to get help from them or anything like that. I think to myself, I'll deal with that at home. But at the same time I understand that the children need the staff if something comes up." 1:4

\subsubsection{Interactions of rejection and violation}

In certain circumstances, family members were rejected or violated by the staff. For example, when the patients' condition turned even more critical, the family members became extremely worried and those who had no family around or had difficulties expressing feelings in the family also had difficulties enduring the situation. The only source of consolation was to be close to the patient as much as possible. Even if family members were promised full access to the unit and patient, this was suddenly restricted and they were reprimanded by the staff in a harsh and rude way. The staff's behaviour was apprehended as insulting. Feelings of helplessness and a failure to trust the staff arose and family members did not have the strength to protest, as they were too vulnerable and dependent. 
"They have no right to stop me. I have the right to meet my husband, definitely, and I'm not in the way. I sit nicely on a chair and if they want me to go out, then I do. $" 4: 1$

"Then she gathered us all in the family room and said that a family with a sick boy needed the room more than we did and then, I don't really know how they think, you know, how they can rate how sick you are. How did you react? We had to leave. We put on our clothes and went ... How did that feel? I was really angry because first we weren't allowed to be in the family room and then when we go in to Mum they feel bothered about you being in there too much." 1:1

\section{Discussion}

The main result of this study is described in two themes: Mutual understanding and Mutual misunderstanding. Whether the family members could understand the information and/or the implicit messages was decisive for their further interactions with the staff. In the first theme, the family members understood the explicit information and implicit messages. These family members felt accepted, well treated and sometimes even consoled by the staff, to which they had an open communication, even if some of them questioned the care. In the other theme, the same kind of interactions were present at the beginning, but resulted in family members' having difficulties understanding the explicit information and/or implicit messages. Thus they drew back or were acting out, leading to misunderstanding with the staff. There was no open communication with the staff and family members felt rejected and even insulted. This result is in accordance with 
Plowfield (1999), who also found two different ways of experiencing the interactions in an ICU, either with uncertainty and loss of situational control or searching for meaning, trying to learn the rules and gaining control by seeking information.

The family members in the present study, who cognitively appraised the situation, understood that there were limits for family members, not to be infringed. They behaved in keeping with this knowledge and it seemed to be in accordance with how staff wanted them to behave. According to Lazarus and Folkman (1994) there are normative expectations about a person's behaviour. Even if the context influences people in similar ways, there are always differences in their thoughts, feelings and behaviour. This highlights how a person in order to understand the environment cognitively must understand its psychological meaning. Those family members who were acknowledged and satisfied by the staff received different kinds of confirmation, which helped them to feel less anxiety. Even if they noticed that some information was contradictory, they trusted the staff. This attention seemed to buffer family members’ stress. Further Lazarus and Folkman (1994) meant that the social environment provides resources, such as support, which the individual can draw upon as an immediate buffer to stress. In order to live well and to survive, the individual must recognize and use available resources. During the encounters the person begins to realize what has happened and what can be done about it, and the coping processes starts. Our study shows how this process is highly valid for family members having an open communication with the staff in ICU.

Some family members who were able to understand explicit information and implicit 
messages could be openly annoyed or critical about the care or the system, without being rejected by the staff. Instead they were accepted and respected by the staff and the other family members. These persons were proud of themselves and were important for the family as some sort of watchdogs. Plowfield (1999) also described spokespersons in families as struggling to be strong and protect the family. According to Lazarus and Folkman (1994) individuals can regulate emotional distress by problem-focused coping, e.g. by using an objective and analytic process to solve problems, but also by using strategies for developing new behaviour or learning new skills. Major stress, e.g. crisis, can make persons use resources they never thought they had. They can gain strength and even grow from stress (Lazarus and Folkman, 1994). In our study the family members' reactions are in line with the different coping strategies among relatives and friends visiting the ICU, as shown by Johansson et al. (2002).

Some of the family members, who understood and were open and humble and were supported and consoled by the staff, showed their suffering openly. Staff being present and giving space for the family members, letting them know that they were not alone, is, according to Norberg et al. (2001), a way to make the other ready for consolation. By sharing the affections, a person can feel consolation.

Family members who had difficulties understanding the information and/or implicit messages became confused and acted cautiously and uneasily. By their behaviour family members did not seem to fulfil the expectations of the staff. Instead of trying to interpret these family members' behaviour, the staff abandoned them. The family members 
thereby lost excessive information and responses of acknowledgement and confirmation from the staff, which made the situation even worse for them. The less information they received, the bigger the threat became and the more they drew back. This negative circle, which Watzlawic et al. (1967) called feedback loops in interactions, is not a cause-effect relationship but circular. Family members' seeking for information is also reported by Hupcey (1999), Plowfield (1999) and Jamerson et al. (1996). According to Lazarus and Folkman (1994) lack of information can lead to overload. When the threat becomes greater, emotion-focused forms of coping are used, e.g. individuals draw back and have a sense of not being in control. In this study, this behaviour of family members was clearly seen in the interactions leading to misunderstanding. The above described scenario can be understood from the result presented by Azoulay et al. (2000), who stated that more than half of the family members of the ICU patients experienced poor comprehension of the information provided by the physicians.

If the condition of the patient became worse, the family members who were avoided by the staff had a desperate need to be close to the patient. For example, when they came to the ICU at times that staff apprehended as inconvenient they were rejected and even insulted by the staff. They did not dare to oppose and were not offered opportunities to express their suffering. According to Norberg et al. (2001), a person who is in despair has lost a sense of meaning and feels like falling apart. This person is in a sense unavailable and has no feeling of togetherness. In present study, the family members who were avoided by the staff had no togetherness with either other family members or the staff. They therefore seemed to desperately seek some sort of togetherness with the 
unconscious patient. The staff did not seem to understand the behaviour of these family members, but interacted with irritation and even insulted them. Eriksson (1994) points out that causing suffering in care is often done unconsciously. The present results show that some family members suffer both from the anxiety relating to the state of the patient and from the interactions with the staff. Eriksson (1994) further states that dignity is experienced when one is able to fulfil one's purpose as a human, which is to be there for another person. If one is hindered in this responsibility e.g. by being ignored, dignity will be insulted and the possibility to be a full human being is diminished.

There is a risk that ICU staff avoid family members, who do not act and behave as expected, and are not able to see their strengths and resources. These kinds of situations arise, according to Wright et al. (1996), between individuals in language and do not reside within individuals. They further describe the traditional hierarchical relationship, which is governed by specific, unspoken and implicit rules, where the nurse is the expert and the family members act from an inferior position.

The strengths of this study are the combined data collection including observations and interviews, treated as a joint text in the analyses. These two data collection methods supplemented and reinforced each other, and revealed a comprehensive picture of the interactions. Observations rely on the observer's perceptions and judgements and can therefore be sensitive to bias (Denzin, 1989). However, to enhance the credibility, the first author trained observing skills before the study started and audio taping was performed during the observations. The first author has worked in ICU and is familiar 
with the context, which can be both an advantage and a risk of "going native” (Agar, 1996). However, in order to enhance the trustworthiness, the interpretation of the data were discussed and interpreted together with the two other authors, who had an outside perspective.

The results of this study can be a starting point for ICU staff to reflect on how family members are met, and e.g. offer opportunities for family members to express their feelings and experiences in a dialogue with the staff. Nurses can thereby gain understanding and respect for family members' different ways of apprehending the situation and thereby diminish suffering. Further research is needed e.g. about the family members' experiences in a longitudinal perspective. Knowledge is also needed in order to highlight how critical illness influences families as a system.

\section{Acknowledgements}

We want to thank the family members for participating in the study. We are also grateful to Alan Crozier for revising the English. This study was supported by grants from Kalmar University and the Association Södra Sveriges Sjuksköterskehem (SSSH). 
Table 1. Examples from the content analysis

\begin{tabular}{|c|c|c|c|}
\hline Meaning unit & $\begin{array}{l}\text { Code: What is it } \\
\text { about? }\end{array}$ & Category & Theme \\
\hline $\begin{array}{l}\text { "What you feel is the } \\
\text { relaxed manner of a staff } \\
\text { member who treats you as if } \\
\text { you knew them from } \\
\text { before" }\end{array}$ & $\begin{array}{l}\text { The family member } \\
\text { feels relaxed and } \\
\text { secure with the } \\
\text { staff. }\end{array}$ & $\begin{array}{l}\text { Interactions of } \\
\text { adjustment and } \\
\text { acknowledgement }\end{array}$ & $\begin{array}{l}\text { Mutual } \\
\text { under- } \\
\text { standing }\end{array}$ \\
\hline $\begin{array}{l}\text { “I don’t think I’ve ever seen } \\
\text { such good staff. They’re just } \\
\text { like you want them to be. } \\
\text { You get close to them } \\
\text { somehow, and they touch } \\
\text { you so that you can let your } \\
\text { feelings come out” }\end{array}$ & $\begin{array}{l}\text { The family member } \\
\text { is content with the } \\
\text { staff and feels } \\
\text { consoled as an } \\
\text { individual. }\end{array}$ & $\begin{array}{l}\text { Interactions of } \\
\text { consolation and } \\
\text { confirmation }\end{array}$ & $\begin{array}{l}\text { Mutual } \\
\text { under- } \\
\text { standing }\end{array}$ \\
\hline $\begin{array}{l}\text { "I was really disappointed. } \\
\text { Nobody can stop me from } \\
\text { going and sitting down } \\
\text { there. That's how it is, isn't } \\
\text { it? There are screens and } \\
\text { drapes. I don't disturb } \\
\text { anybody. I'm just there, I } \\
\text { want to be with my Olle } \\
\text { (cries). And so I will be, yes } \\
\text { sir” }\end{array}$ & $\begin{array}{l}\text { Disappointed wife } \\
\text { prevented by the } \\
\text { staff from visiting } \\
\text { her husband. Feels } \\
\text { insulted and } \\
\text { rejected, but will } \\
\text { not put up with it }\end{array}$ & $\begin{array}{l}\text { Interactions of } \\
\text { rejection and } \\
\text { violation }\end{array}$ & $\begin{array}{l}\text { Mutual } \\
\text { misunder- } \\
\text { standing }\end{array}$ \\
\hline $\begin{array}{l}\text { Observation: Anna (sister) } \\
\text { stands beside the patient. } \\
\text { Lisa (daughter) starts to cry. } \\
\text { The patient wants to get up. } \\
\text { Anna tries to calm the } \\
\text { patient. The staff do } \\
\text { nothing. Anna looks } \\
\text { imploringly at the staff. } \\
\text { Alarm. EN comes. Anna } \\
\text { goes out. } \\
\text { "I don't really expect } \\
\text { anything of the staff, to get } \\
\text { help from them or anything } \\
\text { like that. I think to myself, } \\
\text { I'll deal with that at home. } \\
\text { But the children, I think } \\
\text { they really get too little help } \\
\text { from the staff.” }\end{array}$ & $\begin{array}{l}\text { Situation where the } \\
\text { patient is restless. } \\
\text { The sister tries to } \\
\text { calm the patient. } \\
\text { Gets no help. } \\
\text { Alarm. EN comes. } \\
\text { The sister goes out. } \\
\text { The family member } \\
\text { does not expect } \\
\text { help from the staff } \\
\text { for herself, but } \\
\text { thinks that the } \\
\text { children get too } \\
\text { little support. } \\
\text { Disappointed. }\end{array}$ & $\begin{array}{l}\text { Interactions of } \\
\text { emotional } \\
\text { maladjustment } \\
\text { and non- } \\
\text { acknowledgement }\end{array}$ & $\begin{array}{l}\text { Mutual } \\
\text { misunder- } \\
\text { standing }\end{array}$ \\
\hline
\end{tabular}




\section{References}

Agar, M., 1996. The professional stranger: An informal introduction to ethnography. Academic Press, Inc, San Diego.

Azoulay, E., Chevret, S., Leleu, G., Pochard, F., Barboteu, M., Adrie, C., Canoui, P., Le Gall, J.R. Schlemmer, B., 2000. Half the families of intensive care unit patients experience inadequate communication with physicians. Critical Care Medicine 28, (8), 3044-3049.

Baxter, L.A., 1994. Content analysis. In: Montgomery, B. Duck, S., (Eds.), Studying Interpersonal Interaction. The Guilford Press, London, pp. 239-254.

Bijttebier, P., Vanoost, S., Delva, D., Ferdinande, P. Frans, E., 2001. Needs of relatives of critical care patients: perceptions of relatives, physicians and nurses. Intensive Care Medicine 27, 160-165.

Bogdewic, S.P., 1999. Participant Observation. In: Crabtree, B. F. Miller, W., (Eds.), Doing Qualitative Research. Sage Publications, Thousand Oaks, pp. 47-70.

Burr, G., 1998. Contextualizing critical care family needs through triangulation: An Australian study. Intensive and Critical Care Nursing 14, (4), 161-169.

Catanzaro, M., 1988. Using qualitative analytical techniques. In: Woods, N. F. Catanzaro, M., (Eds.), Nursing Research: Theory and practice. C.V. Mosby Company, St. Louis, pp. 437-456.

Denzin, N.K., 1989. The research act. Prentice-Hall Englewood Cliffs, New Jersey.

Doherty, S. Sandelowski, M., 1999. Focus on qualitative methods. Interviewing children. Research in Nursing and Health 22, 177-185.

Eriksson, K., 1994. Den lidande människan (The suffering human being). Liber Utbildning, Arlöv.

Fox, S. Jeffrey, J., 1997. The role of the nurse with families of patients in ICU: The nurses' perspective. Canadian Journal Cardiovascular Nurse 8, 17-23.

Hupcey, J.E., 1998. Establishing the nurse-family relationship in the intensive care unit. Western Journal of Nursing Research 20, (2), 180-194.

Hupcey, J.E., 1999. Looking out for the patient and ourselves-the process of family integration into the ICU. Journal of Clinical Nursing 8, (3), 253-262.

Jamerson, P.A., 1996. The experiences of families with a relative in the intensive care unit. Heart \& Lung 25, 467-474. 
Jamerson, P.A., Scheibmeir, M., Bott, M.J., Crighton, F., Hinton, R.H. Cobb, A.K., 1996. Experiences in the ICU. The experiences of families with a relative in the intensive care unit. Heart \& Lung 25, (6), 467-474.

Johansson, I., Hildingh, C. Fridlund, B., 2002. Coping strategies when an adult next-ofkin/close friend is in critical care: A grounded theory analysis. Intensive and Critical Care Nursing 18, (2), 96-108.

Kleiber, C., Halm, M., Titler, M., Montgomery, L.A., Johnson, S.K., Nicholson, A., Craft, M., Buckwalter, K. Megivern, K., 1994. Emotional responses of family members during a critical care hospitalization. American Journal of Critical Care 3, (1), 70-76.

Lam, P. Beaulieu, M., 2004. Experiences of families in the neurological ICU: "A bedside phenomenon". Journal of Neuroscience Nursing 36, (3), 142-146, 151-155.

Lazarus, R.S. Folkman, S., 1994. Stress, Appraisal, and Coping. Springer Publishing Company, INC, New York.

Leske, J.S., 1986. Needs of relatives of critically ill patients: A follow-up. Heart \& Lung 15, (2), 189-193.

Molter, N.C., 1979. Needs of relatives of critically ill patients: A descriptive study. Heart \& Lung 8, (2), 332-339.

Norberg, A., Bergsten, M. Lundman, B., 2001. A model of consolation. Nursing Ethics 8, (6), 544-553.

Norris, L.O. Grove, S.K., 1986. Investigation of selected psychosocial needs of family members of critically ill adult patients. Heart \& Lung 15, (2), 194-199.

Plowfield, L.A., 1999. Living a nightmare: Family experiences of waiting following neurological crisis. Journal of Neuroscience Nursing 31, (4), 231-238.

Polit, D.F. Beck, C.T., 2004. Nursing Research. Principles and Methods. Lippincott Williams \& Wilkins, Philadelphia.

Söderström, I.M., Benzein, E. Saveman, B.I., 2003. Nurses' experiences of interactions with family members in intensive care units. Scandinavian Journal of Caring Science 17, (2), 185-192.

Titler, M.G., Cohen, M.Z. Craft, M.J., 1991. Impact of adult critical care hospitalization: Perceptions of patients, spouses, children, and nurses. Heart \& Lung 20, (2), 174182. 
Twibell, R., 1998. Family coping during critical illness. Dimensions of Critical Care Nursing 17, (2), 100-112.

Van Horn, E., 2000. The effect of critical care hospitalization on family members: Stress and responses. Dimensions of Critical Care Nursing 19, (4), 40-49.

Watzlawick, P., Beavin Bavelas, J. Jackson, D.D., 1967. Pragmatics of human communication. W.W. Norton \& Company, New York.

Wright, L.M., Watson, W.L. Bell, J.M., 1996. Beliefs: The heart of healing in families and illness. Basic Books, New York. 